\title{
Etnomatemática e EJA: contextos e práticas evidenciadas em experiências de vida
}

\author{
Ethnomathematics and EJA: contexts and practices evidenced in life \\ experiences
}

\author{
Anderson de Souza Santos ${ }^{1}$ \\ Valesca Corrêa Pereira ${ }^{2}$ \\ Junio Fábio Ferreira ${ }^{3}$ \\ Cristiane Coppe de Oliveira ${ }^{4}$ \\ Leandro de Oliveira Souzd 5
}

\begin{abstract}
Resumo. É comum que alunos da Educação de Jovens e Adultos (EJA), sobretudo aqueles de idade mais avançada, tenham algum tipo de experiência profissional ou vivência em meio rural, sendo este um possível fator condicionante para o seu abandono e atraso escolar. Neste contexto, podemos observar alguns conhecimentos próprios que estes alunos têm e que torna evidente a etnomatemática do saber-fazer, tão comum emsuas próprias experiências de vida. Com base nesta perspectiva, este artigo apresenta os resultados de uma pesquisa realizada com alunos de uma turma multisseriada do primeiro segmento da (EJA), de uma escola pública do município de Ituiutaba/MG. Para tanto, elencamos como principal objetivo um estudo de como a etnomatemática se evidencia nas vivências e experiências que estes alunos têm em meio rural, a partir da análise da transcrição dos discursos proferidos por eles. Isso é algo que foi possível por meio da realização de uma entrevista coletiva nãoestruturada e também pela metodologia de análise textual discursiva. Para tanto, utilizamos como elemento motivador para fomentar os diálogos, discussões e reflexões acerca do tema
\end{abstract}

\footnotetext{
${ }^{1}$ Mestrando do Programa de Pós-graduação em Ensino de Ciências e Matemática (PPGECM), Universidade Federal de Uberlândia (UFU), andersonsouza_s@ @otmail.com

${ }^{2}$ Mestranda do Programa de Pós-graduação em Ensino de Ciências e Matemática (PPGECM), Universidade Federal de Uberlândia (UFU), valesca@ufu.br

${ }^{3}$ Mestrando do Programa de Pós-graduação em Ensino de Ciências e Matemática (PPGECM), Universidade Federal de Uberlândia (UFU), juniofabio5@ hotmail.com

${ }^{4}$ Professora Associada do ICENP/UFU e do Programa de Pós-graduação em Ensino de Ciências e Matemática (PPGECM), Universidade Federal de Uberlândia (UFU), criscoppe@ gmail.com

${ }^{5}$ Professor Associado do ICENP/UFU e do Programa de Pós-graduação em Ensino de Ciências e Matemática (PPGECM), Universidade Federal de Uberlândia (UFU), olilean@ gmail.com
} 
"grandezas e medidas", a exibição de um vídeo didático intitulado "Matemática no sitio" da série "Matemática em toda parte", da TV Escola. Os resultados obtidos apontam para a presença de conhecimentos informais acerca de grandezas e medidas e as suas relações com o Sistema Métrico Decimal.

Palavras-chave. EJA. Etnomatemática. Grandezas. Medidas. Zona rural.

\begin{abstract}
It is common for students of Youth and Adult Education (EJA), especially those of more advanced age, to have some kind of professional experience or experience in rural areas, this being a possible conditioning factor for their abandonment and school delay. In this context, we can observe some of their own knowledge that these students have and that makes evident the ethnomathematics of know-how, so common in their own life experiences. Based on this perspective, this article presents the results of a survey carried out with students from a multiserial class in the first segment of (EJA), from a public school in the municipality of Ituiutaba / MG. Therefore, we list as a main objective a study of how ethnomathematics is evident in the experiences and experiences that these students have in rural areas, based on the analysis of the transcription of the speeches given by them. This is something that was possible through an unstructured collective interview and also through the discursive textual analysis methodology. To do so, we used as a motivating element to foster dialogues, discussions and reflections on the theme "quantities and measures", the display of a didactic video entitled "Mathematics at the site" of the series "Mathematics everywhere", from TV Escola. The results obtained point to the presence of informal knowledge about quantities and measures and their relationship with the Decimal Metric System.
\end{abstract}

Keywords. EJA. Ethnomathematics. Quantities. Measures. Rural area.

\title{
1 Introdução
}

Quando falamos dos alunos da Educação de Jovens e Adultos (EJA), estamos nos referindo a um grupo de pessoas de escolarização básica incompleta ou jamais iniciada, que em razão do não acesso a esta escolarização na idade certa recorrem ao ensino básico na idade adulta ou na juventude.

Em virtude disso, percebe-se nesta modalidade de ensino um conjunto de características próprias que muito se difere das características presentes no ensino regular, como, por exemplo, a diferença de idade entre os alunos matriculados, sobretudo em turmas multisseriadas cuja diferença de idade entre eles pode ser muito grande em alguns casos. 
É importante destacar que existem diversos fatores condicionantes para este atraso escolar dos alunos da EJA. Em face disso, Fonseca 2012 afirma que:

\begin{abstract}
a interrupção ou o impedimento de sua trajetória escolar não lhe ocorre, porém, apenas como um episódio isolado de não-acesso a um serviço, mas num contexto mais amplo de exclusão social e cultural, e que, em grande medida, condicionará também as possibilidades de re-inclusão que se forjarão nessa nova (ou primeira) oportunidade de escolarização. (FONSECA, 2012, p. 14,[2]).
\end{abstract}

Neste contexto, a valorização das suas vivências e saberes culturais se constitui como um fator de extrema importância no processo de ensino e aprendizagem destes alunos, pois é a partir disso que o seu conhecimento prévio, embora informal, passa a ter um novo significado para as suas vidas.

Partindo destes pressupostos, o presente artigo traz os resultados de uma pesquisa realizada com alunos, na faixa etária entre 35 e 82 anos de idade, de uma turma multisseriada do primeiro segmento da EJA de uma escola pública do município de Ituiutaba/MG.

É importante salientar que estes alunos possuem em comum algumas experiências e vivências da zona rural, assim sendo, justificamos a realização desta pesquisa a partir da perspectiva de buscar pela compreensão de como a etnomatemática se evidencia dentro deste contexto, sendo esta a pergunta norteadora que embasa a escrita deste artigo.

Neste sentido, compreendemos que a metodologia de pesquisa mais adequada para o seu desenvolvimento consiste na realização de uma entrevista coletiva não-estruturada, para coleta de dados, e a partir disso a realização de uma análise textual discursiva, por meio da qual podemos compreender a matemática por trás das práticas e experiências cotidianas vivenciadas por estes alunos em meio rural.

Nessa perspectiva, buscamos criar um ambiente de pesquisa o mais natural possível, em que os alunos pudessem agir e se expressar sem medo da sua exposição. Assim, tendo em vista fomentar discussões acerca do tema "grandezas e medidas", exibimos inicialmente um trecho do vídeo educativo "Matemática no sítio" da série televisiva "Matemática em Toda Parte”, exibida pela TV Escola.

Esta série foi criada em 2009 sendo que na sua primeira versão foram produzidos ao todo doze vídeos com as seguintes temáticas: (a) Matemática na comunicação; (b) no sítio; (c) nas feiras e mercados; (d) na cozinha; (e) na escola; (f) no futebol; (g) nos transportes; (h) no parque; (i) nas finanças; (j) na música; (k) na arte; e (l) na construção.

A apresentação desta série foi realizada pelo professor e educador matemático Antônio José Lopes, conhecido como "Bigode", cujo trabalho tem colocado em evidência a aproximação do "saber" com o "fazer" matemático, o que às vezes é imperceptível em situações comuns do nosso cotidiano.

Este é um dos desafios do ensino de Matemática na Educação de Jovens e Adultos, relacionar o conhecimento teórico em sala de aula com o conhecimento prático que estes 
alunos têm de vida. Isto é o que constitui o viés que embasa e norteia o desenvolvimento desta pesquisa.

\section{Etnomatemática e EJA: práticas e saberes}

O termo “etnomatemática” é definido por D'Ambrosio (1998, p. 9,[1]) como “a arte ou técnica (techné = tica) de explicar, de entender, de se desempenhar na realidade (matema), dentro de um contexto cultural próprio (etno)".

Isso é algo que se evidencia com muita facilidade nos alunos da Educação de Jovens e Adultos, sobretudo quando levamos em consideração o contexto sociocultural no qual se inserem e as experiências e conhecimentos que eles têm em suas próprias vidas.

Nessa perspectiva se evidencia uma matemática própria do "fazer de cabeça", o que vai além da concepção de aprendizado intuitivo de conceitos a partir das experiências de vida, "pois seguem uma sequenciação de pensamento e toda uma estrutura matemática" composta por "um conjunto de conceitos e procedimentos que englobam métodos de investigação e raciocínio" (XAVIER e FREITAS, 2019, p.4,[5]).

Com isso percebe-se a inerência destes conhecimentos com suas próprias identidades socioculturais, o que nos obriga, segundo Fonseca (2012, p. 80,[2]) a enxergar estas pessoas como "sujeitos culturais: nos quais se reconhecem as marcas da cultura permeando suas posturas e decisões, intenções e modos do seu fazer e do seu estar no mundo, e, portanto, de suas motivações e recursos de matematicar".

Neste contexto, os aspectos socioculturais garantem uma característica própria desses modos de matematicar, o que se evidencia nas experiências de vida de quem emigra de uma região para outra, como, por exemplo, os nordestinos que vieram trabalhar na região Sudeste do Brasil.

\section{Metodologia}

Os dados apresentados nesta pesquisa foram obtidos por meio da realização de uma entrevista não-estruturada, em que as questões não são apresentadas seguindo a imposição de uma ordem rígida, ou seja, "o entrevistado discorre sobre o tema proposto com base nas informações que ele detém e que no fundo são a verdadeira razão da entrevista" (LÜDKE e ANDRÉ, 1986, p. 33-34,[3]).

Com isso é possível o estabelecimento de um ambiente de aceitação mútua entre pesquisadores e alunos, onde as informações podem fluir de forma notável, natural e autêntica, conforme bem destacam as autoras. É importante salientar que as entrevistas, enquanto instrumento de coleta de dados, se organizam em três modalidades: (a) entrevista 
não-estruturada ou não-padronizada; (b) entrevista semi-estruturada; e (c) entrevista estruturada ou padronizada.

Segundo Lüdke e André (1986, p. 34,[3]), a entrevista não-estruturada ou não-padronizada se caracteriza por dar mais "liberdade de percurso" ao entrevistador, já a entrevista semiestruturada se desenvolve "a partir de um esquema básico, porém não aplicado rigidamente, permitindo que o entrevistador faça as necessárias adaptações”, ao contrário do que ocorre com a entrevista estruturada ou padronizada, em que "o entrevistador tem que seguir muito de perto um roteiro de perguntas feitas a todos os entrevistados de maneira idêntica e na mesma ordem", uma situação que muito se assemelha a aplicação de questionários.

Por outro lado, tão importante quanto à realização da entrevista é a análise dos dados obtidos com a transcrição das falas e expressões proferidas pelos alunos, o que pode ser realizado por meio da análise textual discursiva, que segundo Moraes e Galiazzi (2006), propicia a reconstrução

[...] do objeto da pesquisa e de sua compreensão. Argumenta-se no texto, sempre a partir das vivências de quem passou pelo processo, que a análise textual discursiva cria espaços de reconstrução, envolvendo-se nisto diversificados elementos, especialmente a compreensão dos modos de produção da ciência e reconstruções de significados dos fenômenos investigados (MORAES e GALIAZZI, 2006, p. 118,[4]).

É importante destacar que a compreensão do nosso objeto de pesquisa a partir dessa concepção da análise textual discursiva perpassa também pela necessidade de se compreender as diversas maneiras de matematizar dessas pessoas, o que é permeado por aspectos culturais da vivência de cada uma delas.

\section{As entrevistas: descrição e análise dos discursos}

Esta pesquisa foi realizada com seis alunos e sua aplicação teve início logo após a exibição de um trecho de aproximadamente dez minutos do vídeo "Matemática no sitio", cuja abordagem explorava as atividades do campo partindo de princípios matemáticos como, por exemplo, a conversão de medidas agrárias (hectare, alqueire, léguas) em unidades do sistema métrico decimal.

Neste trecho, em específico, é realizada uma apresentação histórica acerca da criação do Sistema Métrico Decimal, instituído a partir da Revolução Francesa no ano de 1791.

Este sistema foi criado visando padronizar as unidades de medidas de modo que elas se tornassem ao mesmo tempo precisas e universais, uma vez que as unidades não convencionais de medidas que existiam desde os tempos dos gregos e romanos (jarda, braça, 
cúbito, passo, palmo, pé, polegada) acabavam gerando muita confusão entre mercadores, funcionários públicos e cidadãos comuns.

Nessa perspectiva, realizamos logo após a exibição do vídeo uma roda de conversa com estes alunos e a partir daí fizemos alguns questionamentos com intuito de fazer transparecer a etnomatemática presente em suas histórias de vida, de acordo com o tema em questão.

Para preservarmos a identidade dos professores pesquisadores e dos alunos participantes, decidimos identificá-los com nomes fictícios, precedido pelas abreviações de Professor (Prof.), Professora (Profa.), Senhor (Sr.) ou Senhora (Sra.).

\subsection{Descrição e análise dos discursos}

Para que a nossa análise seja a mais fidedigna possível ao que os alunos responderam, descreveremos a seguir todas as respostas proferidas por eles em cada questionamento, tal qual foram formuladas e ditas.

As mediações foram realizadas por dois professores, sendo um professor colaborador, que iremos identificar apenas como Felipe, e a professora regente desta turma, a quem chamaremos pelo nome de Elaine.

Dos seis alunos participantes desta pesquisa, apenas duas alunas não interagiram com o grupo de discussão, acreditamos por assim ser que as mesmas não possuíam as mesmas experiências de vida que os outros quatro participantes, os quais iremos chamar pelos nomes fictícios de Afonso, Levi, Gregório e Fátima.

\subsection{Transcrição dos diálogos}

_Vocês conseguem identificar alguma unidade de medida utilizada naquela época que ainda pode ser utilizada nos dias de hoje? (Prof. Felipe)

_ O negócio do "parmo”. (Sr. Gregório)

_ Igual lá na horta que eu trabalho, na hora de plantar, eu uso é o passo, porque não tinha metro. (Sr. Afonso)

_ É, eu toda vida mexi com horta. (Sr. Afonso)

_ O senhor observou que o apresentador mostra como exemplo uma plantação? E para um agricultor fazer uma plantação ele precisa ter certas medidas e respeitar o espaço de uma planta para outra. Como isso é feito? O senhor pode explicar para gente? (Prof. Felipe)

_ Salsa é uma medida, coentro é outra medida, couve é outra medida. Alface é de 20 centímetros, a couve já é de 50 centímetros de uma da outra. (Sr. Afonso)

_ Como verificar isso Sr. Afonso? (Prof. Felipe) 
_ Porque as folhas delas são largas, se colocar elas perto, elas "embatuma" tudo uma na outra. Prega uma na outra. Agora o coentro já pode ser uns 10 centímetros. Agora não tem a quantidade de sementes. Ele já nasce tudo um pregado no outro. Ele é de cortar. A gente corta ele, pra ele subir de novo. A alface também tem que ter espaço uma da outra, porque se planta ela pequenininha assim, planta pertinho, ela vai crescer não tem espaço pra ela. Aí ela apodrece. Cada planta tem um tamanho. Agora já tem a parte do que é maior. Agora laranja, assim, esses "trem" já tem que o espaço ser maior. Tem que saber o que vai plantar e saber o que vai separar eles. Eu aprendi muito. (Sr. Afonso)

Esse modo de agir utilizando-se de passos para realizar medições que respeitem o modo de crescimento de cada hortaliça nos mostram, segundo D'Ambrosio (1998, p.9,[1]), "a arte ou técnica (techné = tica) de explicar" um conhecimento que na maioria dos casos é passado de uma geração para outra, de pai para filho, ou no sentido inverso, conforme podemos ver no diálogo seguinte.

_ Meu menino mesmo, até pouco tempo, até hoje ainda aprendo, porque tem muitas coisas que eu não sei. Tem uns que eu tenho que perguntar. É igual quantidade de adubo. Tem uns que vai mais quantidade de adubo, outros não vai quase nada. Uns vai calcário, outros já não pode ir. Cada adubo tem o número dele. É HC ..., é justamente para cada planta. Para "mim fazer". Na minha cabeça eu dou conta. (Sr. Afonso)

_. A horta lá é grande. É uma faixa de 50, 70, 80 bandeja do que a gente planta por dia. Planta hoje, daqui uma semana planta outra quantidade, em sequência, enquanto está colhendo ali, a outra aqui já tá no ponto. Termina lá e já vai passar para cá. Aquela que colheu, já torna plantar ela de novo. Faz a sequência. Assim é couve, coentro, tudo que for plantar. (Sr. Afonso)

Nestes dois trechos da fala do Sr. Afonso, podemos perceber a matemática do "fazer de cabeça", que segundo Xavier e Freitas (2019, [5] $)$, envolve a sequenciação do pensamento de forma lógica, o que neste caso requer o uso de estratégias de plantio em um espaço não concebido de forma métrica, mas sim dado pela quantidade de bandejas que ele comporta. Prosseguindo com a nossa entrevista, abrimos espaço para que os outros alunos também falassem um pouco das suas experiências de vida em meio rural, conforme podemos ver nas transcrições descritas a seguir.

_ O Sr. Afonso falou da vivência dele. O que ele faz todo dia na prática. Eu não tenho nem a metade do conhecimento dele, e de como é que se pode fazer tudo isto. Parabéns pelo conhecimento que o senhor tem. Eu não sei se os outros já tiveram a mesma vivência que ele tem. Já tiveram? (Prof. Felipe)

\section{_Eu já. (Sr. Levi)}

_ Mas o senhor planta também, não planta Sr. Levi? Conta um pouquinho para o Prof. Felipe como é esta experiência? (Profa. Elaine) 
_ Eu planto uma coisinha pouquinha, de nada. (Sr. Levi)

_ Mas é medida a quantidade, o tamanho, a distância? (Profa. Elaine)

_ Eu plantava lá no nordeste. Eu plantava feijão, milho, mandioca. Porque a plantação lá do nordeste é diferente da plantação daqui. (Sr. Levi)

_ Milho, aqui eles plantam bem juntinho, e lá no nordeste eles já plantam com um metro de uma planta para a outra. "Bota" quatro caroço dentro de uma cova e um metro de afastamento. Um metro e meio de largura. (Sr. Levi)

_ E aqui não, aqui já planta o milho é um pé junto do outro. Três "parmo" de um pezinho para outro, seis, sete "parmo" de largura. Se ficar junto demais não dá, queima e vira aquela "bagaceira". (Sr. Levi)

_ O senhor sabe por que é diferente? (Prof. Felipe)

_ Porque aqui é junto demais. Porque aqui cada cova deixa um caroço. Lá no nordeste, cada cova deixa quatro caroço. É por isso que planta mais largo. Porque se plantar junto demais cresce uma "toceira em riba" da outra ai. (Sr. Levi) Nestas falas do Sr. Levi, fica evidente as diferenças socioculturais presentes no modo de plantar daqueles que emigram do nordeste para o sudeste, e isso ele bem destaca quando afirma que "a plantação lá do nordeste é diferente da plantação daqui”. Outra questão também interessante é a sua maneira de medir o terreno e assim matematicar por meio de "palmos".

_ O milho assim é porque ele é muito de metro. Ele é um aqui, outro aqui, outro aqui (apontando formando os pontos na mesa). Então as linhas fica mais junto do milho, e vai embora. Então o que nós faz. Nós plantamos, eu plantei lá meio metro, de uma cova na outra e um metro de largura. (Sr. Gregório)

_ E três caroço na cova. (Sr. Gregório)

_ Só que tem na plantadeira, de trator, ela tem uma chapa que cai a medida certinha um do outro. Não é que vai caindo um "em riba" do outro, cada vez que ela roda vai caindo, ela vai tocando e vai caindo. Dá uma diferença de 15 centímetros, 20 centímetros. Vai depender também do clima, porque o clima de lá é mais seco, aqui já pega mais chuva. Então não tem problema porque não falta água para eles, né? (Sr. Afonso)

Neste último trecho do diálogo podemos perceber as marcas da cultura que permeia as decisões e posturas destes "sujeitos culturais", conforme define Fonseca (2012,[2]), sobretudo quando eles compreendem as questões climáticas como um fator condicionante para as suas ações.

O uso de estimativas quanto ao número mínimo de sementes que podem ser plantadas, considerando-se não apenas o espaço destinado à plantação, mas também as questões climáticas e da qualidade do solo, é algo que se evidencia em suas falas.

_ O ideal é que se plantem quantas sementes então? De milho. (Prof. Felipe)

_ A gente que planta manualmente, de dois a três caroços. (Sr. Gregório) 
_ A (Sra. Fátima) planta milho no fundo de casa também. Não planta? (Profa. Elaine)

_ O ano passado eu plantei. Esse ano ainda não. (Sra. Fátima)

_ E ai o Prof. Felipe está perguntando qual é o número necessário de sementes por cova. Quando você planta, qual é o número por cova? (Profa. Elaine)

_ Três. (Sra. Fátima)

_ Três? Para mim é quatro. Tem gente que planta até com cinco. (Sr. Levi)

_ Agora milho a gente planta com três caroços, mais se ele tiver bom. Se ele tiver fraquinho, ai pode por quatro, cinco, né? Porque um nasce, outro não nasce. (Sra. Fátima)

_ Para mim é três milho, feijão, qualquer coisa. Lá no meu quintal tinha um pé de manga e deu sombra, aí deu umas espiguinhas bem pequenininhas. (Sra. Fátima)

_ Se a terra for ruim a gente planta mais larga. Se a terra for pouca, a gente planta mais estreita para economizar mais a terra. E se a terra for muita, muita terra, a pessoa vai e planta mais largo. Exemplo, você tem uma terrinha boa, não vai plantar a lavoura mais larga, planta mais estreita. Um pezinho de feijão aqui, outro ali. (Sr. Levi)

Nestes diálogos apresentados, percebe-se maneiras peculiares e próprias de realizar as plantações, o que abrange não somente a otimização de espaço, mas também de tempo.

Nos diálogos seguintes podemos perceber que o uso das unidades de medidas não convencionais ainda é algo comum nas questões relativas ao campo como, por exemplo, as expressões "cuia", "braça quadrada" e "tarefa".

_ Se a minha terra é mais que a sua aí eu vou plantar mais largo para eu terminar mais ligeiro e também tem muita terra, planta à vontade. Se você vai plantar uma cuia de feijão. "Nois" lá chama cuia de feijão, se você vai plantar dez quilos de feijão. (Sr. Levi)

_ Por exemplo, você tem uma tarefa, "nois" bota dez quilos de feijão nessa tarefa. Se eu tiver doze quilos eu vou economizar aquela terra para plantar os doze quilos mais lá uma tarefa são vinte e cinco braça quadrada. Vinte e cinco aqui e vinte e cinco assim, tudo quadrado. Tem que economizar a terra para plantar os doze quilos. Se tiver só os dez quilos "bota" só os dez quilos. Mas se der os doze quilos, tenho que "botar" ele todinho naquela tarefa. (Sr. Levi)

_Ele trouxe uma nova medida, “Tarefa”. (Prof. Felipe)

_ Lá no Nordeste um quadro chama quadro, aqui chama como? É, um hectare. Um hectare aqui, lá é quatro tarefa. Um quadro lá são seis tarefas e aqui são seis hectares. (Sr. Levi)

_ Muda de um estado para o outro. O senhor é do nordeste, quando vem aqui para o sudeste já tem essa diferença. Como foi aquele exemplo do alqueire mineiro, paulista e baiano. (Prof. Felipe)

_ O paulista é o dobro do mineiro, e o baiano o dobro do paulista. Mineiro (24.000 $\left.\mathrm{m}^{2}\right)$, paulista $\left(48.000 \mathrm{~m}^{2}\right)$ e baiano $\left(96.000 \mathrm{~m}^{2}\right)$. (Prof. Felipe) 
Esta relação de proporcionalidade aplicada entre diferentes medidas agrárias havia sido apresentada no início do vídeo e ao final de todas as discussões também pôde ser evidenciada nas falas destes alunos.

De modo geral compreendemos que a habilidade que eles demonstram ao realizarem conversões ou equivalência entre diferentes grandezas e medidas é algo que ocorre de modo natural passado de geração em geração, em outras palavras podemos dizer que trata-se de um conhecimento socioculturalmente construído.

\section{Considerações finais}

De acordo com a transcrição das falas de cada um destes alunos, levando-se em consideração as suas experiências de vida em meio rural, podemos elencar três situações que evidenciam a etnomatemática e o "saber fazer" matemático de cada um deles, como: (a) uso de unidades métricas não convencionais com relação de proporcionalidade com as medidas métricas convencionais; (b) cálculo de estimativa quanto ao número mínimo de sementes que devem ser plantadas para se garantir certa produtividade; e (c) noções de área baseada em medidas métricas não convencionais.

Assim, ao retomarmos a nossa pergunta de pesquisa sobre como a etnomatemática se evidencia neste contexto de experiências de vida, compreendemos que o modo que essas pessoas têm "de se desempenhar na realidade (matema), dentro de um contexto cultural próprio (etno)", conforme define D’ Ambrosio (1998, p. 9,[1]), é fruto de suas necessidades de agir sobre o meio nos quais se inserem, permeados fortemente pelas questões socioculturais.

Neste sentido, ressaltamos a valorização das vivências e saberes culturais que estes alunos trazem para a sala de aula como um elemento motivador para a sua permanência na escola. Uma educação que não parte do zero, mas que leve em consideração o rico conhecimento que estes alunos trazem das suas próprias experiências de vida.

\section{Referências}

[1] D’AMBROSIO, U. Etnomatemática: arte ou técnica de explicar e conhecer. 4. ed. São Paulo: Ática, 1998.

[2] FONSECA, M. da C. F. R. Educação Matemática de Jovens e Adultos: especificidades, desafios e contribuições. Belo Horizonte: Autêntica, 2012.

[3] LÜDKE, M.; ANDRÉ, M. E. D. A. Pesquisa em educação: abordagens qualitativas. São Paulo: EPU, 1986. 
[4] MORAES, R.; GALIAZZI, M. do C. Análise textual discursiva: processo reconstrutivo de múltiplas faces. Ciência \& Educação. Bauru, v. 12, n. 1, p. 117-128, 2006.

[5] XAVIER, F. J. R.; FREITAS, A. V. Saberes matemáticos e permanência na EJA. Revista Brasileira de Educação Básica. Belo Horizonte, v. 4, n. 12, p. 1-9, 2019.

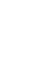

Aceito em 20 abr. 2020 